\title{
Effect of Repeated In Vitro Transfer of Pasteurella haemolytica A1 on Encapsulation, Leukotoxin Production, and Virulence $\dagger$
}

\author{
MARTHA J. GENTRY,${ }^{1}$ ANTHONY W. CONFER, ${ }^{2 *}$ AND REBECCA C. CRAVEN ${ }^{3}$ \\ Departments of Veterinary Parasitology, Microbiology, and Public Health, ${ }^{1}$ Veterinary Pathology, ${ }^{2}$ and Botany and \\ Microbiology, ${ }^{3}$ Oklahoma State University, Stillwater, Oklahoma 74078
}

Received 24 July 1986/Accepted 24 September 1986

\begin{abstract}
Pasteurella haemolytica serotype 1 was transferred daily for 128 serial passages on both unsupplemented brain heart infusion agar and the same basal medium supplemented with bovine blood, horse serum, and yeast extract. Repeatedly transferred cultures were shown to retain the ability to produce both capsular material and leukotoxin. Furthermore, intact organisms were found to be as toxic in vitro for bovine leukocytes and as virulent for mice as unpassaged cultures. These results indicate that the precaution of using only freshly isolated cultures in the study of this organism may not be necessary.
\end{abstract}

Pasteurella haemolytica biotype A serotype 1 is the major cause of the severe fibrinous pneumonia associated with shipping fever of cattle. Several bacterial factors have been implicated as important in the pathogenesis of this disease. The bacterium elaborates a polysaccharide capsule $(6,8)$. The presence of the capsule has been demonstrated to be age dependent (10) and has been suggested as a possible virulence factor of the organism (24). Another attribute ascribed to the bacterium as a potential virulence factor is its ability to produce a leukotoxin which is toxic for bovine pulmonary alveolar macrophages $(3,18)$ and peripheral blood leukocytes $(4,16)$.

Beginning with reports on the pneumococcus in the early 1920 s, it has commonly been believed that continued passage of bacterial pathogens on laboratory medium may result in decreased encapsulation $(2,7,15)$ and a loss of virulence $(13,23)$. Prolonged incubation of a bovine isolate of $P$. haemolytica on blood agar plates has been reported to cause a dissociation of the organism from a predominantly smooth to a predominantly rough form, resulting in a loss of virulence for mice (25). However, another group of researchers reported that a smooth ovine isolate of $P$. haemolytica was passaged in culture continuously for over 6 months without dissociation to a rough form (5). The serotype of the organism was not specified in any of these studies. The purpose of the studies reported here was to examine the effect of daily repetitive in vitro transfer on the encapsulation, leukotoxin-producing capacity, and virulence of $P$. haemolytica serotype 1 .

\section{MATERIALS AND METHODS}

Microorganism and culturing procedures. The organism used throughout the study was $P$. haemolytica biotype A serotype 1 , originally isolated from a feedlot calf. A lyophilized culture of the organism was reconstituted and plated on either unsupplemented brain heart infusion (BHI) agar (Difco Laboratories, Detroit, Mich.) or the same basal medium supplemented with $5 \%$ bovine blood, $10 \%$ horse serum (Hazleton Dutchland, Inc., Denver, Pa.), and 1\% yeast hydrolysate (ICN Pharmaceuticals, Cleveland, Ohio) (SBHI). A single isolated colony from each type of medium

\footnotetext{
* Corresponding author.

† Journal article 5042 from the Agricultural Experiment Station, Oklahoma State University, Stillwater.
}

was used to transfer the culture daily to a fresh plate of the same type of medium. All plates were incubated at $37^{\circ} \mathrm{C}$ in an atmosphere of $5 \% \mathrm{CO}_{2}$. At regular intervals, a colony from each type of medium was also suspended in phosphatebuffered saline (PBS; pH 7.2) and was used to inoculate four plates of the same medium for confluent growth. After $6 \mathrm{~h}$ of incubation, the growth from one plate was suspended in a small amount of distilled $\mathrm{H}_{2} \mathrm{O}$ and stained to determine degree of encapsulation by the Maneval technique as described previously (10). The remaining three plates were incubated for $18 \mathrm{~h}$, after which the growth was removed with a cotton swab and suspended in $3 \mathrm{ml}$ of BHI broth containing $15 \%$ glycerol (Sigma Chemical Co., St. Louis, Mo.). These suspensions were frozen at $-70^{\circ} \mathrm{C}$ and were used as the inocula for experiments in which comparisons were made between repeatedly transferred cultures. Agglutinability of the transferred cultures was determined by a rapid plate agglutination procedure with chicken antiserum to $\boldsymbol{P}$. haemolytica serotype 1 (11).

Leukotoxin production. Toxins were prepared by the method of Shewen and Wilkie (21). Briefly, organisms grown to logarithmic phase in BHI broth were incubated for $1 \mathrm{~h}$ at $37^{\circ} \mathrm{C}$ in RPMI 1640 medium supplemented with $7 \%$ fetal bovine serum. The cultures were then centrifuged $(13,500 \times$ $g$ for $15 \mathrm{~min}$ ), and the supernatants containing leukotoxin were filter sterilized and frozen immediately at $-20^{\circ} \mathrm{C}$. Extinction endpoints were determined for each toxic culture supernatant to quantitate total toxic activity by a modification of a previously described ${ }^{51} \mathrm{Cr}$ release method (12). Briefly, serial twofold dilutions (1/2 to $1 / 256)$ of the culture supernatants were made in RPMI 1640 medium in 96-well microtiter plates (Cell Wells; Corning Glass Works, Corning, N.Y.). The volume of diluted supernatant remaining in each well was $180 \mu \mathrm{l}$. Dilutions were performed simultaneously on six supernatants in duplicate with a 12-channel micropipette (Titertek; Flow Laboratories, Inc., McLean, Va.). From a suspension of ${ }^{51} \mathrm{Cr}$-labeled bovine peripheral blood leukocytes, $90 \mu \mathrm{l}$ was added to each well, and the plates were incubated for $1 \mathrm{~h}$ at $37^{\circ} \mathrm{C}$ in a $5 \% \mathrm{CO}_{2}$ atmosphere. The plates were then centrifuged at $200 \times g$ for 10 min, and $200 \mu \mathrm{l}$ of supernatant from each well was assayed for radioactivity in an automated gamma counter (Searle Analytical, Inc., Des Plains, Ill.). The leukotoxin extinction endpoint was defined as the highest supernatant dilution 

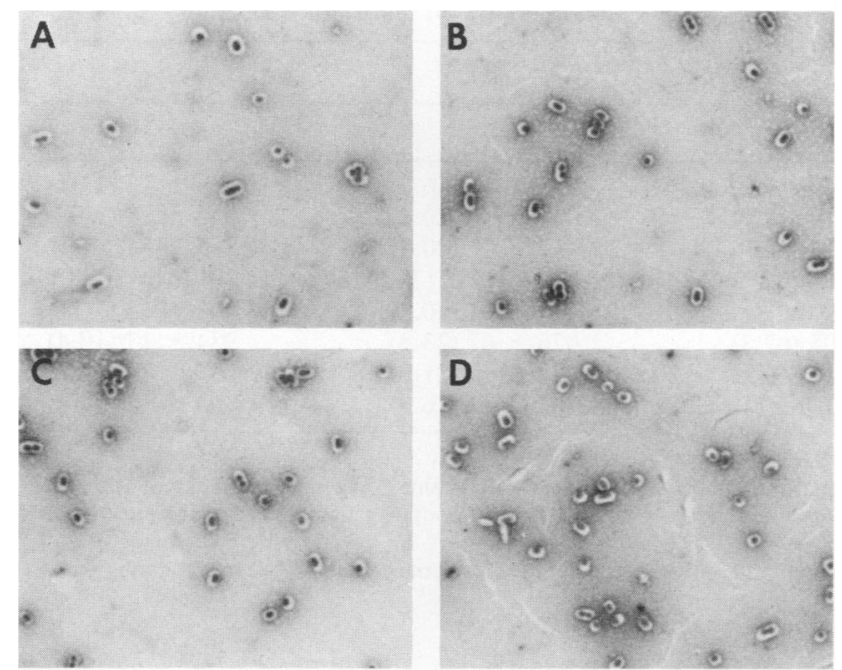

FIG. 1. P. haemolytica stained by the Maneval method $(\times 900)$ Cells were grown for $6 \mathrm{~h}$ on solid medium. (A) Transfer 1 on BHI agar. (B) Transfer 128 on BHI agar. (C) Transfer 1 on SBHI medium. (D) Transfer 128 on SBHI medium. Cells from all four cultures appear to be equally well encapsulated.

eliciting a ${ }^{51} \mathrm{Cr}$ release of at least $50 \%$ of a total release control (4 N NaOH).

In vitro toxicity for bovine leukocytes. Mixed peripheral blood leukocytes were isolated from heparinized bovine blood and labeled with $\mathrm{Na}_{2}\left[{ }^{51} \mathrm{Cr}\right] \mathrm{O}_{4}$ (ICN Pharmaceuticals, Inc., Irvine, Calif.) as previously described (12). The washed, labeled cells were suspended in RPMI 1640 medium at a concentration of $5.8 \times 10^{6}$ cells per ml. Each culture to be tested was grown for $4.5 \mathrm{~h}$ in $\mathrm{BHI}$ broth at $37^{\circ} \mathrm{C}$ on a rotary shaker. The organisms were collected by centrifugation $(13,500 \times g$ for $20 \mathrm{~min})$ and were suspended in RPMI 1640 medium containing $7 \%$ fetal bovine serum to a standardized optical density at $650 \mathrm{~nm}$ of $0.750 \pm 0.004$. The suspensions were found to contain $1.9 \times 10^{8}$ to $4.7 \times 10^{8}$ $\mathrm{CFU} / \mathrm{ml}$ as determined by a spot plate technique.

Four serial 10-fold dilutions of organisms were prepared in serum-supplemented medium from each culture in duplicate. Samples $(180 \mu l)$ of each dilution were placed in quintuplicate wells of 96-well tissue culture plates. Ninety microliters of the ${ }^{51} \mathrm{Cr}$-labeled leukocyte suspension was added to each well, and the plates were incubated for $1 \mathrm{~h}$ at $37^{\circ} \mathrm{C}$ in an atmosphere of $5 \% \mathrm{CO}_{2}$. After incubation, the plates were centrifuged and the well contents were harvested and counted as in the extinction endpoint assay. Mean 4-min test counts from all 10 wells containing like dilutions of a given suspension were used to calculate the percent killing of the leukocytes as follows: \% killing $=[$ (test count - medium control count)/(total release control count - medium control count)] $\times 100$.

Mouse virulence study. Groups of 10 male 38- to 40-day-old Swiss Webster mice (Charles River Breeding Laboratories, Portage, Mich.) were injected intraperitoneally with $0.5 \mathrm{ml}$ of a mixture containing equal volumes of a saline suspension of $P$. haemolytica and a $7 \%$ solution of swine gastric mucin (Sigma; 22). Four cultures were used, including transfers 1 and 128 grown on either SBHI (transfers S1 and S128) or BHI (transfers B1 and B128) medium. The organisms were harvested after $6 \mathrm{~h}$ of growth on the appropriate medium to make a PBS suspension with an optical density at $650 \mathrm{~nm}$ of $0.755 \pm 0.002$. Each group of mice received a single dilution of a given suspension ranging from $10^{0}$ to $10^{-4}$. Control groups of five mice each received either a mixture of equal volumes of $\mathrm{PBS}$ and an undiluted culture of transfer $\mathrm{S} 1$ or transfer B1 or a mixture of PBS and swine gastric mucin. The mice were observed, and deaths were recorded for $72 \mathrm{~h}$ after inoculation. The $50 \%$ lethal dose was calculated for each culture by the method of Reed and Muench (20).

Statistical analysis. Analysis of variance was performed on values from the leukocyte assay. For treatment groups in which $P<0.05$, differences in treatment means were compared by the least significant difference test.

\section{RESULTS}

Comparison of encapsulation. Capsule strains performed every 4 to 7 transfers showed no discernible differences in the degree of encapsulation after 128 transfers on either basal or enriched medium (Fig. 1). In addition, transfers S128 and B128 showed no diminution of agglutinability with antiserum to $P$. haemolytica serotype 1 .

Comparison of leukotoxin production. The extinction endpoints for the leukotoxins from each culture were between $1 / 32$ and $1 / 128$, with no loss of toxinogenicity due to repeated transfer (Table 1 ).

Toxicity of organisms for bovine leukocytes. When leukocytes were exposed to eight viable transfer cultures of $\boldsymbol{P}$. haemolytica at four concentrations each, there were slight variations in measured toxicity among the cultures. At certain dilutions, the variations proved to be significantly different (Table 2). However, no culture was consistently more or less toxic than the others within its medium group.

Virulence of transferred organisms for mice. When groups of mice were injected with five concentrations of $P$. haemolytica from transfer cultures $\mathrm{S} 1, \mathrm{~S} 128, \mathrm{~B} 1$, and B128 in swine gastric mucin, there were no major differences in virulence among the cultures (Table 3 ). The $50 \%$ lethal dose calculated for the cultures ranged from $4.9 \times 10^{5}$ to $1.1 \times 10^{6}$ CFU. All five mice receiving PBS plus swine gastric mucin

TABLE 1. Comparison of selected extinction endpoints of leukotoxins produced by $P$. haemolytica repeatedly transferred on laboratory medium

\begin{tabular}{|c|c|}
\hline $\begin{array}{l}\text { Culture medium } \\
\text { and transfer no. }{ }^{a}\end{array}$ & $\begin{array}{l}\text { Extinctior } \\
\text { endpoint } \\
\text { (reciproca }\end{array}$ \\
\hline \multicolumn{2}{|l|}{ SBHI } \\
\hline $\mathrm{S} 1 \ldots \ldots \ldots$ & 64 \\
\hline S13 ......... & 64 \\
\hline S27 ......... & 64 \\
\hline S47 ......... & 64 \\
\hline S75 ......... & 64 \\
\hline S89......... & 64 \\
\hline S103.......... & 32 \\
\hline S117......... & 128 \\
\hline S128.......... & 64 \\
\hline \multicolumn{2}{|l|}{ BHI } \\
\hline B1.. & 128 \\
\hline B7 $\ldots \ldots$ & 128 \\
\hline B14.......... & 128 \\
\hline B21......... & 64 \\
\hline B27........ & 128 \\
\hline B47......... & 64 \\
\hline B128 $\ldots \ldots \ldots$ & 128 \\
\hline
\end{tabular}

${ }^{a}$ Cultures transferred daily for the number of days indicated.

${ }^{b}$ Endpoints are expressed as the highest dilution of leukotoxin causing a ${ }^{51} \mathrm{Cr}$ release from bovine leukocytes of at least $50 \%$ of a total release control (4 N NaOH). 
TABLE 2. Toxicity of $P$. haemolytica for bovine peripheral blood leukocytes after passage on laboratory medium

\begin{tabular}{|c|c|c|c|c|c|}
\hline \multirow{2}{*}{$\begin{array}{c}\text { Culture } \\
\text { transfer } \\
\text { no. }{ }^{a}\end{array}$} & \multirow{2}{*}{$\begin{array}{c}\text { Mean viable } \\
\text { count } \\
\left(10^{8} / \mathrm{ml}\right)\end{array}$} & \multicolumn{4}{|c|}{ Toxicity $^{b}\left(\%\right.$ killing) at bacterial dilution ${ }^{c}$ of: } \\
\hline & & $10^{1}$ & $10^{2}$ & $10^{3}$ & $10^{4}$ \\
\hline S1 & 4.7 & $1,805 \pm 155(89.6)$ & $1,466 \pm 167(57.0)$ & $997 \pm 41(16.2)$ & $839 \pm 23(1.8)$ \\
\hline S47 & 3.5 & $1,779 \pm 67(87.2)$ & $1,467 \pm 110(58.9)$ & $1,044 \pm 83(20.4)$ & $840 \pm 28(1.9)$ \\
\hline S89 & 4.2 & $1,960 \pm 162(100.0)$ & $1,499 \pm 113(61.8)$ & $1,047 \pm 75(20.7)$ & $877 \pm 31^{d}(5.3)$ \\
\hline S128 & 2.0 & $1,749 \pm 98(84.5)$ & $1,504 \pm 108(62.2)$ & $1,133 \pm 122^{d}(28.5)$ & $895 \pm 44^{d}(6.9)$ \\
\hline B1 & 3.3 & $1,809 \pm 93(89.9)$ & $1,483 \pm 99(60.3)$ & $1,043 \pm 63(20.3)$ & $897 \pm 33(7.1)$ \\
\hline B47 & 3.9 & $1,763 \pm 108(85.7)$ & $1,505 \pm 105(62.3)$ & $1,076 \pm 67(23.3)$ & $934 \pm 17(10.4)$ \\
\hline B87 & 1.9 & $1,910 \pm 103^{d}(99.1)$ & $1,606 \pm 73^{e}(71.5)$ & $1,057 \pm 40(21.6)$ & $887 \pm 24(6.2)$ \\
\hline B128 & 2.9 & $1,781 \pm 75(87.4)$ & $1,544 \pm 67(65.8)$ & $1,105 \pm 74(26.0)$ & $904 \pm 37(7.7)$ \\
\hline
\end{tabular}

${ }^{a}$ Cultures were transferred daily for the number of days indicated on SBHI (S) or BHI (B) agar.

${ }^{b}$ Toxicity is expressed as counts per 4 min of ${ }^{51} \mathrm{Cr}$ released from labeled leukocytes after exposure to the organisms. Values represent the mean of 10 counts from duplicate assays each prepared in quintuplicate. The numbers in parentheses represent the percent killing of the leukocytes calculated from the mean count compared with that of a total-release control $(4 \mathrm{~N} \mathrm{NaOH})$.

${ }^{c}$ Serial 10 -fold dilutions were prepared from a bacterial suspension standardized to a common optical density. Statistical comparisons were made among values at the same dilution of organisms grown on the same medium.

${ }^{d}$ Value is significantly $(P<0.05)$ higher than others at the same dilution within that medium group.

${ }^{e}$ Value is significantly $(P<0.05)$ higher than all except that for B128.

remained healthy, whereas three of the five mice receiving PBS plus $2.0 \times 10^{8}$ organisms from transfer culture S1 and all five mice receiving PBS plus $3.5 \times 10^{8}$ organisms from transfer culture $\mathrm{B} 1$ died.

\section{DISCUSSION}

$P$. haemolytica transferred daily up to 128 times on a solid, highly enriched laboratory culture medium was shown to retain its ability to produce both capsular material and leukotoxin. Encapsulation was demonstrated visually by a staining procedure as well as by the agglutinability of the organisms with an antiserum specific for the $P$. haemolytica capsular serotype (11). These results do not concur with the statement in Bergey's Manual of Systematic Bacteriology that the carbohydrate capsules of $P$. haemolytica "are frequently lost after several subcultures" (8). Rather, they support the cultural stability of the oganism as reported by Biberstein et al. (5). The capacity for leukotoxin produced by organisms from cultures transferred 128 times possessed as much total toxic activity as toxin produced by organisms transferred only once.

Because the highly supplemented SBHI culture medium contained many of the components (serum and blood) encountered in an in vivo system, a second series of transfers was initiated on unsupplemented BHI medium. Again, there was no diminution of encapsulation or toxinogenesis. There was also little if any difference in the measured parameters

TABLE 3. Virulence of $P$. haemolytica for mice after passage 1 or 128 times on laboratory media

\begin{tabular}{lrrrr}
\hline $\begin{array}{l}\text { Bacterial } \\
\text { dilution }^{a}\end{array}$ & \multicolumn{4}{c}{ No. of animals dead $b /$ total no. of animals after transfer } \\
\cline { 2 - 5 } & \multicolumn{1}{c}{$\mathrm{S} 1$} & $\mathrm{~S} 128$ & $\mathrm{~B} 1$ & $\mathrm{~B} 128$ \\
\hline $10^{0}$ & $9 / 10$ & $9 / 10$ & $9 / 10$ & $10 / 10$ \\
$10^{-1}$ & $10 / 10$ & $8 / 10$ & $9 / 10$ & $10 / 10$ \\
$10^{-2}$ & $9 / 10$ & $7 / 10$ & $8 / 10$ & $9 / 10$ \\
$10^{-3}$ & $7 / 10$ & $9 / 10$ & $9 / 10$ & $9 / 10$ \\
$10^{-4}$ & $1 / 10$ & $0 / 10$ & $1 / 10$ & $0 / 10$ \\
\hline
\end{tabular}

a Serial 10-fold dilutions were prepared of organism suspensions containing $0.8 \times 10^{9}$ to $1.4 \times 10^{9}$ viable bacteria per $\mathrm{ml}$.

${ }^{b}$ Cumulative deaths recorded for $72 \mathrm{~h}$ postinfection. The $50 \%$ lethal doses (in CFU) for the transfers were as follows: S1, $4.9 \times 10^{5} ; \mathrm{S} 128,1.1 \times 10^{6}$; B1, $7.0 \times 10^{5}$; and $\mathrm{B} 128,4.8 \times 10^{5}$.

c Cultures were transferred 1 or 128 times on BHI agar (B1 and B128) or SBHI medium (S1 and S128). between organisms grown on basal versus supplemented medium.

The leukocyte toxicity and mouse virulence tests were performed to examine the effect of repeated transfer on the pathogenicity of the bacterium. The interactions of $P$. haemolytica with bovine leukocytes have not been completely characterized. The toxic effects of the organisms on neutrophils (4) and mononuclear leukocytes (16) have been shown to be dose related and are presumed to be due primarily to the liberation of leukotoxin into the medium. To determine if there were differences in the composite effect of the organisms in addition to leukotoxin production, a ${ }^{51} \mathrm{Cr}$ release assay was used to determine toxicity of the intact organisms on bovine leukocytes. The results agreed with those found in the leukotoxin assay in that there was no indication that the transferred organisms were less effective in killing leukocytes than were those freshly isolated from a diseased animal. The mouse virulence test further corroborated those results by showing that the transferred organisms were at least as pathogenic for mice as were unpassaged organisms.

There were statistically significant differences found at certain bacterial dilutions between the ${ }^{51} \mathrm{Cr}$ released by bovine leukocytes after exposure to live bacteria from repeatedly transferred cultures and that released after fewer transfers. However, such discrepancies probably do not reflect actual differences in culture toxicity. The necessity of standardizing the bacterial suspensions on the basis of optical density, which is only a rough estimate of the number of organisms in a culture, introduces an inherent error in the experimental design. Duplicate suspensions of each organism were used, with the results from like suspensions pooled in an attempt to negate the effects of this problem. When results from duplicate suspensions were statistically compared with one another, significant differences were found sporadically which could not be explained by differences in the measured viable cell counts of the suspensions. Therefore, we feel that an actual difference in toxicity among the organisms should be manifested at all or several dilutions for the bacterial passages tested. None of the cultures were considered significantly more toxic than any of the others according to this criterion. Furthermore, there was no trend toward decreasing toxicity as the cultures were repeatedly transferred.

Virulence of the organisms for mice was also found not to 
be diminished by repetitive transfer of the culture. $P$. haemolytica is not a normal pathogen for laboratory mice. Mixtures of the bacterial inoculum with swine gastric mucin (22) or hemoglobin (9) and injection of the mice with ferric ammonium citrate sufficient to saturate their serum transferrin with iron (1) are methods reported to promote lethal infections of mice with this organism. A somewhat surprising result of the present study was that 8 of the 10 control mice injected with $P$. haemolytica (transfer 1 from both media) without mucin died. This result may be because the mice were injected with organisms from 6-h (encapsulated, logarithmic-phase) cultures rather than the 16- to 24-h (stationary-phase) cultures used by previous investigators (1, 9, $19,22)$. Organisms from stationary-phase cultures have been shown to have minimal amounts of capsular material (10), perhaps making them more susceptible to phagocytosis by mouse peritoneal phagocytes. A smooth strain of $P$. haemolytica covered with a surface or envelope antigen was similarly shown to be more virulent for mice than was a nonsmooth strain (5).

In conclusion, 128 repeated transfers of $P$. haemolytica on laboratory medium failed to reduce the organism's ability to make two products assumed to be virulence factors, namely, capsular material and leukotoxin. The transferred organisms were also as pathogenic as the freshly isolated culture in both an in vitro toxicity assay and an in vivo virulence study. In the past, our laboratory and others $(14,17)$ have been careful to use cultures which have been freshly isolated from a diseased animal for leukotoxin preparation and challenge exposure studies. These results indicate that passage of the organism in a susceptible animal may not be necessary to maintain toxicity and virulence.

\section{ACKNOWLEDGMENTS}

This work was supported in part by special grants 83-CRSR-22195 and 85-CRSR-2-2618 from the U.S. Department of Agriculture.

We thank René Simons and Sheryl Holland for technical assistance, Mark Hall for statistical analyses, and Mary Seelig and Kathy Phillips for typing the manuscript.

\section{LITERATURE CITED}

1. Al-Sultan, I. I., and I. D. Aitken. 1984. Promotion of Pasteurella haemolytica infection in mice by iron. Res. Vet. Sci. 36:385-386.

2. Amies, C. R. 1951. The envelope substance of Pasteurella pestis. Br. J. Exp. Pathol. 32:259-273.

3. Bensen, M. L., R. G. Thomson, and V. E. O. Valli. 1978. The bovine alveolar macrophage. II. In vitro studies with Pasteurella haemolytica. Can. J. Comp. Med. 42:368-369.

4. Berggren, K. A., C. S. Baluyut, R. R. Simonson, W. J. Bemrick, and S. K. Maheswaran. 1981. Cytotoxic effects of Pasteurella haemolytica on bovine neutrophils. Am. J. Vet. Res. 42:1383-1388.

5. Biberstein, E. L., M. E. Meyer, and P. C. Kennedy. 1958. Colonial variation of Pasteurella haemolytica isolated from sheep. J. Bacteriol. 76:445-452.

6. Carter, G. R. 1956. A serological study of Pasteurella haemolytica. Can. J. Microbiol. 2:483-488.
7. Carter, G. R. 1957. Studies on Pasteurella multocida. II. Identification of antigenic characteristics and colonial variants. Am. J. Vet. Res. 18:210-213.

8. Carter, G. R. 1984. Genus I. Pasteurella Trevisan 1887, 94, ${ }^{\mathrm{AL}}$ Nom. Cons. Opin. 13, Jud. Comm. 1954, 153, p. 552-557. In N. R. Krieg and J. G. Holt (ed.), Bergey's manual of systematic bacteriology, vol. 1. The Williams \& Wilkins Co., Baltimore.

9. Chengappa, M. M., G. R. Carter, and T. S. Chang. 1983. Hemoglobin enhancement of experimental infection of mice with Pasteurella haemolytica. Am. J. Vet. Res. 44:1545-1546.

10. Corstvet, R. E., M. J. Gentry, P. R. Newman, J. A. Rummage, and A. W. Confer. 1982. Demonstration of age-dependent capsular material on Pasteurella haemolytica serotype 1. J. Clin. Microbiol. 16:1123-1126.

11. Frank, G. H., and G. E. Wessman. 1978. Rapid plate agglutination procedure for serotyping Pasteurella haemolytica. J. Clin. Microbiol. 7:142-145.

12. Gentry, M. J., A. W. Confer, and J. A. Kreps. 1985. Simple visual assay for determination of Pasteurella haemolytica cytotoxin neutralizing antibody titers in cattle sera. J. Clin. Microbiol. 22:968-972.

13. Gillespie, J. H., and J. F. Timoney. 1981. Hagan and Bruner's infectious diseases of domestic animals, 7th ed, p. 28. Cornell University Press. Ithaca, N.Y.

14. Gilmour, J. S., G. E. Jones, A. G. Rae, and M. Quirie. 1986. Comparison of single strains of four serotypes of Pasteurella haemolytica biotype $\mathrm{A}$ in experimental pneumonia of sheep. Res. Vet. Sci. 40:136-137.

15. Jann, K., and O. Westfall. 1975. Microbial polysaccharides, p. 25. In M. Sela (ed.), The antigens, vol. 3. Academic Press, Inc., New York.

16. Kaehler, K. L., R. J. F. Markham, C. C. Muscoplat, and D. W. Johnson. 1980. Evidence of cytocidal effects of Pasteurella haemolytica on bovine peripheral blood mononuclear leukocytes. Am. J. Vet. Res. 41:1690-1693.

17. Knight, H. D., E. L. Biberstein, and M. Allison. 1969. The role of capsular and somatic antigens in immunization of mice against Pasteurella haemolytica infection. Cornell Vet. 59:55-64.

18. Markham, R. J. F., and B. N. Wilkie. 1980. Interaction between Pasteurella haemolytica and bovine alveolar macrophages: cytotoxic effects on macrophages and impaired phagocytosis. Am. J. Vet. Res. 41:18-22.

19. McKinney, K. L., A. W. Confer, J. A. Rummage, M. J. Gentry, and J. A. Durham. 1985. Pasteurella haemolytica: purification of saline-extractable proteins by isoelectrofocusing. Vet. Microbiol. 10:465-480.

20. Reed, L. J., and H. Muench. 1938. A simple method of estimating fifty per cent endpoints. Am. J. Hyg. 27:493-497.

21. Shewen, P. E., and B. N. Wilkie. 1982. Cytotoxin of Pasteurella haemolytica acting on bovine leukocytes. Infect. Immun. 35:91-94.

22. Smith, G. R. 1958. Experimental infections of Pasteurella haemolytica in mice and their use in demonstrating passive immunity. J. Comp. Pathol. 68:455-468.

23. Troy, F. A., II. 1979. The chemistry and biosynthesis of selected bacterial capsular polymers. Annu. Rev. Microbiol. 33:519-560

24. Walker, R. D., T. W. Schultz, F. M. Hopkins, and M. J. Bryant. 1984. Growth phase-dependent phagocytosis of Pasteurella haemolytica by bovine pulmonary macrophages. Am. J. Vet. Res. 45:1230-1234.

25. Wessman, G. E. 1964. Interrelationships of smooth and nonsmooth variants in the dissociation of Pasteurella haemolytica. J. Bacteriol. 88:356-360. 